\title{
LA POLÍTICA DE NUEVA NORMALIDAD BAJO EL LENTE DE LA FILOSOFíA SOCIAL
}

\author{
NEW NORMALITY POLICY UNDER SOCIAL PHILOSOPHY SCOPE \\ (iD) Jorge Luis Montero Rodríguez ${ }^{*}$ \\ jorge.montero9270@alumnos.udg.mx \\ ${ }_{1}^{1}$ Universidad de Guadalajara, Guadalajara, México
}

*Correspondencia: Jorge Luis Montero Rodríguez. Email: jorge.montero9270@alumnos.udg.mx

Recibido: 22.11.2020 | Aprobado: 15.12.2020

\section{RESUMEN}

La actual crisis epidémica ha puesto en jaque la confiada robustez del sistema social contemporáneo basado en la política, ciencia, tecnología y el libre mercado. El presente ensayo expone una observación crítica a la política de Nueva Normalidad desde una visión socio-filosófica. Se asume que esta política es una regresión a fenómenos gubernamentales que muestran continuidad en una retórica reinventada e impositiva de un comportamiento sociomoral. Las nociones de reformismo de Estado, etopolítica y resiliencia sirven de argumentos para amparar dicha tesis. Por último, se ofrece una discusión propositiva sobre la subversión y la antifragilidad de las sociedades como estrategia política contra una Nueva Normalidad que promete un tiempo futuro, pero no un espacio socioeconómico y político diferente.

Palabras clave: Antifragilidad, nueva normalidad, política, subversión.

\begin{abstract}
The current epidemic crisis has put into a hard spot the robustness of the contemporary social system based on politics, science, technology and free-market. The present text shows a critical observation to the current New Normality policy from a social-philosophical vision. This policy is a regression to certain governmental phenomena for gives it continuity and imposes certain social-moral behavior using a reinvented rhetoric. State-reformism, ethopolitics and resilience are notions to serve as arguments to support this thesis. At the end, I offer a purposeful discussion about subversion and antifragility of societies as a way of proposing a political strategy against a New Normality, because the New Normality is not a change, but a policy that promises a future time but not a different socioeconomic political space.
\end{abstract}

Keywords: Antifragility, new normality, policy, subversion. 


\section{INTRODUCCIÓN}

Desde inicio del 2020 hemos vivido un período de emergencia sanitaria en la mayoría de los países del mundo. Las medidas gubernamentales para controlar la infestación viral del SARS-CoV2 han dejado en evidencia las fallas de los Estados y del capitalismo. Empero, esta no es una situación inusual en lo que va de civilización; hemos pasado por varias situaciones críticas similares: la peste negra del siglo XIV, las guerras mundiales, la guerra fría y el MAD atómico, las crisis económicas de 1929 y de 2008, entre otras. Todas ellas exigieron a la población comportamientos excepcionales según las circunstancias, y hacia la persuasión de tales comportamientos fueron encaminadas las políticas gubernamentales en sus momentos. Recuérdese que, durante la amenaza nuclear en tiempos de guerra fría, la sociedad estadounidense fue inducida a un comportamiento de miedo y autoprotección.

En la situación crítica actual de pandemia, lo característico de la politización del comportamiento social para Latinoamérica es el discurso de la 'nueva normalidad' como una manera de vida social gestionada y diferenciada, pero conservadora, de la manera 'normal' de vida anterior. Ello ha puesto etiqueta a las actividades socioeconómicas reactivadas para afrontar la decadencia provocada por el confinamiento. Según la CEPAL, Argentina, Brasil y Perú serían los países con mayor caída económica en la región suramericana y, en reacción, sería necesario recuperar la actividad productiva, de servicio y laboral que antes dinamizaba a la normalidad (Barría, 2020).

Luego de que el presidente López Obrador expresó el paso hacia una 'nueva normalidad' para la sociedad mexicana, el Plan Gradual hacia la Nueva Normalidad en la Ciudad de México fue presentado en mayo del 2020 con la expresa determinación, bajo reglamentación, de recuperar la economía y otras actividades sociales. De ello derivó la implementación de un semáforo epidemiológico que regiría las acciones por estados en la nación (Gobierno de la Ciudad de México, 2020).

Igualmente, el presidente chileno en abril anunció el plan especial de reactivación del sector educativo y público como parte de la estrategia gubernamental hacia una nueva normalidad. Sin embargo, la esperada efectividad tuvo reversión negativa cuando los casos de Covid-19 aumentaron (García, 2020). La política había surgido de manera vertical sin socialización alguna y con tácitas intensiones de apaciguar las protestas sociales aún efervescentes. Mostró una cara de presentación retórica que afirmaba el seguro retorno post-confinamiento, pero terminó siendo totalmente insegura (García, 2020; Durán, 2020).

En Guatemala sucedió más o menos lo mismo. Fonseca (2020) recuperó datos censales, económicos y epidemiológicos para argumentar la doble cara de la política de Nueva Normalidad, deudora de un modelo neoliberal privativo y expoliador, generador de desigualdades sociales y pobreza; política esta que no pretende abandonar el modelo neoliberal mientras maquilla el defectuoso sistema de salud resultante y pone en manos del pueblo guatemalteco la responsabilidad de su cuidado.

Estos ejemplos dejan entrever que la mencionada política es, ontológicamente, un movimiento de regresión a estructuras funcionales previas a partir de un estadio de crisis particular con preservación trascendente, sin cambios radicales en el sistema social. Por 
demás, parece estar respaldada en la moral social del autocuidado y la responsabilidad, lo cual conserva una tradicionalidad económica y política macro-social, a la vez que modifica la conducta micro-social.

Para la región latinoamericana, el cuidado es colectivo, pero individualizado si tomamos en cuenta la asincronía de la percepción del riesgo y la inculpación intersocial en los países. Por ejemplo, en Perú y Bolivia, azotadas duramente por el virus, un $80 \%$ de sus poblaciones expresó preocupación en los riesgos, en cambio en México, igualmente azotada, la percepción fue baja. A tono, en Perú la gente asumió mayoritariamente la responsabilidad propia en las alzas epidémicas, mientras que en México cada persona culpabilizó a los demás de ello (Galindo, 2020). Esto evidencia un claro comportamiento individualista y discriminatorio en un contexto social que excede connotativamente a la crisis sanitaria actual.

El presente ensayo problematiza esta inducción de un comportamiento inculpatorio desde la individualidad a partir de la puesta en marcha de la política de Nueva Normalidad que populariza un discurso disociativo de la verdadera realidad socioeconómica y política que se debe desnormalizar. El texto no es una evaluación de la mencionada política en un país específico, sino una crítica a los preceptos retóricos que la mantienen consistente a pesar de su contradicción si advertimos que ontológica y moralmente es incoherente con la problemática social que caracteriza a las sociedades latinoamericanas de hoy.

La tesis que se pretende argumentar es la siguiente: la política de Nueva Normalidad no es un cambio tal y como es presentada por la retórica política, sino una regresión a fenómenos gubernamentales con continuidad en una praxis reinventada que impone determinado comportamiento socio-moral.

En favor de exponer ciertos argumentos que sustenten esta tesis, la estructura del ensayo está conformada como sigue: 1) se presenta una explicación filosófica de la ontología de la normalidad, 2) se argumenta acerca de la figura reformista de la mencionada política y la retórica que le da consistencia, y 3) se propone una discusión en torno a la subversión y antifragilidad social como vías de solución a la disyuntiva generada por dicha retórica que sirve de cierra argumental al ensayo.

La Nueva Normalidad parece ser una estrategia política para esperar por una vacuna que devuelva la 'normalidad' trastocada y, a la vez, ella es una vacuna política contra la insubordinación social que exigiría rendir cuentas al capitalismo neoliberal y al Estado.

\section{¿Qué es la normalidad?}

En primera instancia quiero presentar una reflexión sobre lo que implica hablar de una normalidad-otra diferente a lo que asumíamos anteriormente como 'normalidad'. Lo que llamamos normalidad es una entidad abstracta surgida de juicios y criterios que tenemos los seres humanos de la repetitividad de un fenómeno o situación que experimentamos. Semánticamente, normalidad alude a la cualidad de algo que no varía, o varía muy poco, y en sentido general, es considerado como algo estándar o bien conocido. Cuando tenemos un conocimiento irrevocable de algo, es porque ello se mantiene en un cierto estado o estados que nos lleva a inferir su casi invariabilidad y a reconocerlo 
constantemente. Por extensión, la normalidad llega a ser la entidad total que reúne a todas esas cosas con apariencias y comportamientos interactivos que nos son normales $u$ ordinarios. La normalidad es instantáneamente opuesta a lo novedoso o extraordinario. Luego, transcurrido un tiempo necesario de interacción, las novedades se nos vuelven habituales y pasan a ser parte de la normalidad. En este sentido interactivo, la distinción entre algo-que-nos-es-anormal y la normalidad es temporal y espacial. Un cambio de espacio será percibido como extra-normal si consideramos normal a lo admisible como el medio o entorno a la mano de costumbre humana. En compensación, el constante cambio del tiempo en su devenir nos permite adaptarnos a lo extraño y aceptar lo nuevo como parte de la normalidad. Los diseños e implementaciones de políticas públicas se sostienen en estos principios espacio-temporales. De manera objetiva, cualquier política de Estado instaura un espacio sociopolítico en un tiempo particular para cada país o nación.

Por ejemplo, el Estado-nación instauró un espacio sociopolítico reforzado en la ideología liberal y la identidad nacional; el Estado de Bienestar intersecó su espacio político con el espacio económico para reformar los mecanismos de protección y bienestar social; los Estados dictatoriales aplican una política coercitiva en espacio sociopolítico de limitaciones y represiones sociales. Cada uno de ellos, en sus momentos, definió una 'normalidad' consecuente a rupturas y cambios temporales que fueron asimilados adaptativamente por las poblaciones en espacios mutables.

Con esto quiero ilustrar que en el ámbito político también los principios normalizadores de tiempo y espacio son fundamentales, tanto como lo son para la dinámica económica y la vida social.

La ontología de la normalidad, como más o menos esbocé antes, se refiere a la acumulación de entidades y fenómenos que, en nuestras vidas, vivimos los seres humanos de manera usual y repetida, que conocemos, asimilamos y reconocemos a pesar de los sutiles cambios que puedan manifestar. De ahí emerge una moral de la normalidad que posiciona a los seres humanos en una esfera de convivencia respetuosa y tolerante a los cambios que exigen de la responsabilidad compartida al asumir lo normal como un movimiento espacio-temporal coherente con la intersubjetividad y las diversas culturas.

Esto plantea la complejidad del vivir humano en sociedad y en un planeta regido por el inexorable devenir temporal y la movilidad espacial. El mero hecho de vivir es un instante tras otro de cambios espacio-temporales. No hay posibilidad ontológica de recuperar el 'tiempo perdido de vida' ni el espacio libre sin confinamiento sin percibir los cambios correspondientes en tiempo y espacio. Por tanto, no hay una 'normalidad estable e invariable' a la cual regresar, porque la normalidad se funda en los constantes cambios que experimentamos y admitimos como parte del vivir diario. Que la retórica haga uso del término de manera homóloga a lo inmutable y deseable así, es otra cosa.

Ahora llevemos esta reflexión al contexto sociopolítico actual.

Se cree que hasta que no sea inventada y aplicada una vacuna, no retornaremos a la normalidad socialmente aceptada y vivida antes. Mientras eso llega, los gobiernos imponen medidas de suspensión, limitación y aislamiento en las sociedades. 
Evidentemente, estas circunstancias nos parecen anormales porque se salen de los cambios cotidianamente aceptados. Los criterios para argumentar esta anormalidad son: la imposibilidad de llevar vida social en espacios públicos, asistir al trabajo y continuar con las rutinas de consumo. Esta secuencia de actividades son las que nos parecen normales en las sociedades contemporáneas.

Lo que anhelamos de esa anterior 'normalidad' es consumir libre e indiscriminadamente sin restricciones de tiempo ni de lugar, es regodearnos con la explotación laboral que diariamente nos exige vida y ofrece dinero, es contaminar con los vehículos de combustión interna el ambiente de nuestro planeta. Hoy no extrañamos acumular likes, conversar en el ciberespacio, ni criticar a otros desde la seguridad de la fachada virtual; todo eso lo tenemos aún en demasía como aspecto inmutable de nuestra 'normalidad', y aun así queremos recuperar la 'vida normal'.

Es cierto que ahora los espacios de consumo [tiendas online], de trabajo [teletrabajo] y de socialización [plataformas de videoconferencias y reuniones] son otros, y por ello supone que vivimos un cambio; pero estos espacios han sido así desde mucho antes. Hoy lo que se ha incrementado es su tiempo de uso y ello llevará, a la larga, a convertirlo en una normalidad. Sin embargo, no toda persona hace uso de ellos con la misma intensidad, lo cual implica hablar de que aún hoy persiste la diversidad de normalidades. Hay personas, fundamentalmente en países pobres, que han continuado trabajando de manera tradicional porque el consumo de sus familias depende de lo que ganen diariamente. Por demás, ante la actual inseguridad económica, muchas familias han tenido que cambiar sus hábitos de consumo y ni siguiera acceden a las tiendas online de moda.

Se debe entender que las normalidades son diversas según las diversidades individuales, económicas, políticas y socioculturales. Por ejemplo, mientras en Latinoamérica muchas de las normalidades colectivas han sido trastocadas, el Tíbet no ha perdido su normalidad. Esta es una de las regiones del mundo con menos casos de Covid19, además de que la vida de sus habitantes es diferente, en premura e impacto, que la vida occidental.

El imaginario de normalidad colectiva que tenemos en occidente está fuertemente determinado por la dinámica de mercado y consumo que caracteriza al estilo de vida neoliberal globalizado, por la presencia política del Estado separado pero no ajeno de la esfera socioeconómica y sociocultural a pesar de las excepciones [Cuba, Venezuela y Bolivia], la confianza en la ciencia y la tecnología, así como en ideologías y creencias que condicionan el vivir diario [catolicismo, cosmovisiones indígenas, socialismo, y otras]. Por ello, las ataduras a la vida normal pasada es una añoranza casi general, a diferencia del imaginario oriental que tiene al cambio constante y regenerativo como principio espiritual de vida - basta referir la efectiva reacción frente al Covid-19 de Japón, Corea del Sur y Singapur gracias a que habían asumido a los brotes virales como eventos normales en la vida de sus sociedades.

Para América Latina, los mencionados condicionantes estructurales y etológicos de sus sociedades sirven de cimientos para propugnan una política de Nueva Normalidad que remodele ciertas cuestiones sociales sin alterar aquellas políticas y económicas que 
reproducen al imaginario de normalidad colectiva. Esta política retoma la narrativa del libre mercado, las libertades individuales, la protección popular y los derechos humanos para argumentar una retórica híbrida de asistencialismo estatal y autorresponsabilidad social [ver, por ejemplo, el Plan Gradual hacia la Nueva Normalidad en la Ciudad de México (Gobierno de la Ciudad de México, 2020)].

Es por esto que ella representa ontológicamente un movimiento de regresión a estructuras funcionales previas que intentan preservar un espacio específico en un tiempootro.

\section{RETÓRICA HÍBRIDA}

Políticamente, hablar de Nueva Normalidad induce en las expectativas y voluntades sociales la idea de cambio, de avance hacia un tiempo-otro con mejoras sustanciales. Empero, si bien presupone un salto en el tiempo social, no plantea lo mismo para el espacio económico y sociopolítico. El espacio de vida social parece quedar políticamente conservado como ha sido antes.

En este punto hay que analizar, en términos de lo político, lo que significa la normalización de la normalidad, y para ello me apoyaré en las reflexiones de Boaventura de Sousa sobre el Estado y la transformación social, por ser, a mi juicio, reflexiones estructurales [históricas], praxiológicas [filosóficas] y conductuales [sociológicas]. De Sousa (2006) nos dice que heredamos de la modernidad dos paradigmas de transformación social: la revolución y el reformismo. Mientras la revolución es fruto del actuar social, el reformismo le pertenece al Estado cual agente que incide en el cambio social. El Estado funge como sujeto encargado de solucionar el problema surgido en la sociedad.

El reformismo como vía política tiene un debate extensísimo, por ello me limitaré a hacerle breves honores. Desde la perspectiva histórica, está directamente ligado al surgimiento del Estado moderno. Por ejemplo, el reformismo borbónico situó al Estado como el único agente de las reformas, vinculado al hacer económico y social, cargado de optimismo y con una retórica oficial propia (Guimerá, 1996). Por su parte en la filosofía, está asociado al pragmatismo si se entiende que la filosofía de las acciones útiles es la búsqueda situacional de la verdad en los cambios reformadores, revolucionarios o radicales. La distinción entre estos dos grupos ha sido según el papel otorgado a los asuntos filosóficos en los conflictos culturales e históricos donde la crítica social y política comparten espacio (Del Castillo, 2003).

Para la sociología política, el reformismo constituye un mecanismo político para lograr cambios o transiciones graduales, no radicales, en las sociedades. De ello surgen conductas y comportamientos sociales subsecuentes, ya sea desde una visión cristiana democrática, socialista o neoliberal (D’Antonio y Pike, 1964; González, 2018).

Con esta brevísima contextualización, más que presentar un estado de la cuestión, aspiro a mostrar la amalgama crítica que se pude lograr a partir de una postura filosóficasociohistórica de la praxis reformista de los Estados si reconocemos que las medidas políticas son históricas en la dimensión social de su implementación. La política de Nueva Normalidad se perfila como una praxis reformista particular, por eso el lente analítico que 
ofrece De Sousa (2006) es adecuado para analizarla sociohistóricamente en principio. Se presupone que dicha política ha sido implementada como una estrategia gubernamental para solucionar un problema social, esta vez epidémico, que problematiza a las sociedades infestadas por el SARS-CoV2.

Ahora bien, vale aclarar que "el reformismo se basa en la idea de que sólo es normal el cambio social que puede ser normalizado" (De Sousa, 2006, p. 212), y dicha normalización tiene lógica simétrica entre la mejora y la repetición.

En la repetición anida la lógica del orden, mientras que en la mejora se persigue el progreso. Orden y progreso son compatibles, por lo que la repetición y la mejora se complementan. La secuencia intercalada entre los momentos de repetición y aquellos de mejora hace del cambio social un compás normal. Entonces el autor plantea paradójicamente que "si una determinada condición social se repite no mejora, y si mejora no se repite" (De Sousa, 2006, p. 213); no obstante, la política reformista es repetitiva y gana fuerza.

Una explicación a tal tenacidad reformista es que el cambio social normal es opaco y permite que la reforma política depare en variadas interpretaciones según la asunción de mejoras y repeticiones. Las variadas interpretaciones generan conflictos que sirven de motivos para implementar las reformas. La repetición y la mejora conducen a una normalización del cambio social gracias al sistema educativo, al derecho y a la identidad cultural como dispositivos de normalización. Adicionalmente, la percepción de los cambios, como fenómenos fugaces que responden a fenómenos prolongados, reafirma la indeterminación temporal e inevitabilidad de los cambios que ganan legitimidad (De Sousa, 2006).

Adicionalmente, la complementación entre repetición y mejora hace del cambio social "un juego de suma positiva" (De Sousa, 2006, p. 213). Esto quiere decir que la inclusión social aumenta y supera a la exclusión social, lo cual contrarresta lo negativo con lo positivo. Además, el carácter ambiguo de las medidas reformistas no permite distinguir entre sus efectos capitalistas y los anticapitalistas. Más aún, la opacidad e indeterminación del cambio social dota de plasticidad y abstracción a las políticas reformistas, haciéndolas aplicables y funcionales con total credibilidad en variados contextos sociales.

Varios son los elementos dados por De Sousa (2006) que sirven para analizar esta política de Nueva Normalidad como parte de una reforma social, a saber: 1) el cambio social indeterminado en el tiempo, 2) la recursividad causal de la implementación de la política reformista, y 3) la manipulación de positividades, ambigüedades y aplicabilidades.

La Nueva Normalidad es un cambio social que no fue planeado con anticipación a la emergencia epidemiológica, por eso hoy es una realidad sociopolítica imprevista e impredecible a futuro. En los primeros campases de la pandemia, las medidas gubernamentales fueron detener la mayoría de las actividades económicas y dictar el confinamiento domiciliario para mantener el distanciamiento social. Estas medidas detonaron conflictos sociales entre una población reaccionaria y otra dócil. Por ejemplo, en varios estados de E.E.U.U. las protestas de ciudadanos anti-confinamiento y antimáscaras han deparado en enfrentamientos con grupos obedientes y policías (Shepherd, 
2020; Stewart, 2020). También en Perú han aumentado las protestas por motivos económicos y de salud pública asociados a los trabajos mineros ya la atención médica (Reuters, 2020).

Tales conflictos representaron un problema más a solucionar por medio del discurso disuasivo y apaciguador de la Nueva Normalidad. Con esto último se cierra el ciclo recursivo causal de la implementación de la política reformista.

A su vez, en todo el período de atención al Covid-19, la manipulación de aspectos positivos [la gestión y atención gubernamental] para encubrir los negativos que sentaron las bases de la crisis [perduración del binomio Estado y mercado neoliberal], junto con la manipulación de criterios políticos que ganan credibilidad gracias al pánico social sin importar sus eficiencias funcionales, son elementos sistematizados que le proporcionan prominencia a la política de Nueva Normalidad.

Un ejemplo relevante es la atención ofrecida por el Estado uruguayo a su pueblo, elogiada por el director del Fondo Monetario Internacional y por otras organizaciones (AFP, 2020), mientras la avenencia del Estado con la mercantilización neoliberal continúa (Vecinday, 2017). El país entró en emergencia sanitaria en marzo y las medidas gubernamentales, en sus inicios, tuvieron buena aceptación pública, pero luego decayó la confianza ciudadana (Redacción de El País, 2020). Posterior a la política de Nueva Normalidad implementada en junio, la confianza de los uruguayos subió a un $65 \%$ (Redacción de Montevideo Portal, 2020).

Operativamente, tres son los mecanismos estratégicos que De Sousa (2006) adujo del desempeño reformista del Estado: 1) confianza, 2) legitimidad y 3) acumulación. Puestos ellos en contexto actual, es como sigue:

1. La confianza de la sociedad en un Estado que gestiona los riesgos y las oportunidades es suficiente para validar la implementación de la política de Nueva Normalidad en el tiempo actual de riesgo, no previsto ni planificado.

2. La lealtad del pueblo en la gestión gubernamental, que deja en manos del Estado la administración de las vidas civiles y la seguridad, lo legitima como solucionador del problema epidemiológico apremiante y de los conflictos sociales que puedan aparecer.

3. La acumulación ha pasado a ser un criterio de 'justicia conveniente' y exigencia social de quienes cumplen con las medidas sanitarias contra quienes no. Ello ha sido facilitado en gran medida por la exageración de lo positivo y la acentuada difuminación de bordes cívicos en situaciones de crisis y pánico social. La convicción política nacionalista manifiesta una acumulación de normas nacionales que sacan a flote la xenofóbica.

La Nueva Normalidad cumple con los elementos para ser considerada una política reformista excepcional o atípica si se quiere. El cambio social propuesto no deja de ser normalizado desde la lógica de la mejora y el discurso persuasivo de la repetición de la crisis sanitaria; y así, la realidad política puesta ante nuestros ojos no deja de ser normal. Con esto se valida uno de los elementos retóricos: el asistencialismo estatal. 
El segundo elemento de esta retórica política es la autorresponsabilidad social. Identifico en ella dos orientaciones conductuales: hacia el auto-cuidado y hacia la resiliencia colectiva. La primera es deudora de la etopolítica, o política del comportamiento individual con su vida, popularizada en la sociedad norteamericana de mediados del siglo XX.

Rose (2001) fue su principal teórico. Él analizó cómo lo biopolítico mutó en estrategias de individualización de la salud y la auto-responsabilidad como actualizaciones bio-políticas. Los Estados neoliberales establecieron políticas conductuales personales para delegar, en el compromiso individual, las promesas de bienestar físico. Tal etopolítica se caracterizó por el manejo político del riesgo poblacional sustentado en la distinción binaria entre lo normal y lo patológico, los grupos sociales sanos y los insanos.

Por medio del manejo estratégico de la raza, padecimientos patológicos y la herencia genética en los 'inaceptados', la biopolítica fundó los fundamentos etopolíticos de la normalidad en la ideología de lo genéticamente adecuado, sin riesgos y seguro a futuro, dejando todo lo opuesto en el espectro de lo anormal. "La emergencia de nuevas ideas respecto de lo que los seres humanos son, lo que deberían hacer y lo que pueden esperar" (Rose, 2012, p. 30) fundó los preceptos de un tipo de normalidad social. Las subjetividades fueron cambiadas y con ello cambiaron la convivencia social reajustada ahora a las obligaciones, derechos y expectativas individuales sobre la vida. Se llegó así a una ética social que buscaba afianzar valores etológicos del vivir.

Hoy la política de Nueva Normalidad tiene como objetivo minimizar los riesgos de salud. Por un lado, pretende evitar el colapso del sistema sanitario en los países, y por otro, dictar medidas sociales para evitar el contagio masivo; siempre hasta tener una vacuna efectiva contra el SARS-CoV2.

Entre las medidas está: evitar salir innecesariamente de casa, usar cubrebocas o protectores similares en espacios públicos y mantener una distancia prudente entre personas (Gobierno de la Ciudad de México, 2020). En especial estas medidas son de carácter social, pero de cumplimiento individual. Representan una estrategia etopolítica de responsabilizar a las personas del estado saludable de sí mismas y de otros. Y si bien estas medidas no discriminan en su cumplimiento, la desigualdad social en los países latinoamericanos hace esa sucia tarea. Basta mencionar que gran parte de las poblaciones deben salir a trabajar para la subsistencia diaria y esto les impide permanecer en casa; algo que sí cumplen las personas de clase alta con seguridad monetaria. Por demás, el uso del cubrebocas se ha vuelto un dilema ético, en algunos estados y países se orientó de manera obligatoria a pesar de las incongruencias para aceptar su efectividad en la prevención (Arteta, 2020; ONU Noticias, 2020). Si bien la cuestión ética en estos tiempos de pandemia expone variadas aristas, una preminente es la tocante al cuidado de sí mismo, de los otros y por los otros que plantea diversos dilemas (Figueroa, 2020). Dicho dilema ético afecta directamente a la población civil, pero también podemos identificar otro en torno a la normalidad que afecta al sistema social entero. Este dilema está dado por la no confirmación explícita del cambio fáctico experimentado por el sistema, adoptando, por el contrario, una estrategia de ocultamiento de la verdad ontológica detrás de una verdad discursiva que refina la semántica del proceso y los efectos fácticos. Según esto, el dilema 
ético está en divulgar una normalidad nueva coherente con la retórica de continuidad, pero incoherente con los ontológicos cambios necesarios y radicales de re-novación. Incluso el Estado es afectado por este dilema aunque no lo perciba de esa manera, pues cae en descrédito ante la mirada popular.

La Nueva Normalidad no es renovadora en cuanto al modelo socioeconómico que conserva; mantiene las piezas fundamentales que le dan funcionamiento al modelo para no perderlo por completo con la crisis epidémica y retomarlo luego en toda su funcionalidad. Por un lado, ese modelo económico, a pesar de evidenciar sus fracasos medioambientales y sociales, ostenta su capacidad revigorizadora y reinventiva en cada crisis. Por otro lado, la ética capitalista continúa afianzada al dinero como valor y organizador de la vida en sociedad. Ambos pilares hoy sopesan a la Nueva Normalidad como política socioeconómica.

De manera estructural, ha sido la determinación de este modelo económico en las vidas humanas lo que cimentó algunos de los padecimientos crónicos que con más frecuencia han contribuido al agravamiento de la enfermedad Covid-19 y a la muerte de los pacientes (Gobierno de Jalisco, 2020). Obesidad, diabetes e hipertensión arterial, provocadas en su mayoría por hábitos alimenticios desequilibrados, el estrés constante y desequilibrios medioambientales, son las principales patologías 'normales' en mexicanos, estadounidenses y españoles. Sus enlaces con la Covid-19 lleva hoy a hablar de sindemia en vez de pandemia (Redacción Médica, 2020).

En términos etopolíticos, los Estados hoy fungen como habilitadores, facilitadores y animadores que interviene en las vidas mediante la política de Nueva Normalidad. El poder pastoral es puesto en los especialistas sanitarios, médicos y bioquímicos (Rose, 2001). Recae en los individuos la responsabilidad de proteger sus vidas y las economías locales, por lo que se evocan los principios de la resiliencia personal y colectiva para impulsar los esfuerzos en tiempos de crisis. Hacia el comportamiento resiliente de las poblaciones va dirigida la política de Nueva Normalidad (EFE, 2020).

Esta política aboga por mantener un actual estado social con nivel bajo de gravedad que pueda ser revertido a futuro y propiciar el retorno al estado socioeconómico anterior. La enfermedad ha sido el fenómeno perturbador o disruptivo de la aparente estabilidad socioeconómica de las sociedades —aparente porque muchas de las sociedades latinoamericanas están muy lejos de ser estables a causa de la brecha económica y social que les caracteriza- La prometida vacuna contra el SARS-CoV2 será el momento de viraje hacia el retorno; hasta entonces, la Nueva Normalidad busca potencializar, reforzar y proveer las capacidades resilientes necesarias en las poblaciones para superar la crisis actual y asegurar el retorno posterior.

La crítica aquí está en no dejarnos engañar con la positividad del concepto, pues, si bien la posee, ha sido utilizado políticamente en favor de intereses económicos capitalistas. Evans y Reid (2016) llevaron a crítica esta negativa y puntualizaron que la resiliencia ha servido para manipular y moldear a la sociedad contemporánea; ha servido para fundar subjetividades patológicas en la inseguridad y el peligro que, por demás, ha sido instaurada políticamente como algo a lo que el sujeto no puede asegurarse en absoluto, sino enfrentarlo y ganar fuerza de ello. 
Las personas políticamente en resiliencia son refundadas en su condicionalidad de autoprotección ante las amenazas, no como sujetos políticos que pueden cambiar las circunstancias. El discurso neoliberal les convence de la imposibilidad de una seguridad prolongada y de la factibilidad de ser resilientes. Con ello, el Estado deja de ser pastoral para ceder la responsabilidad de protección a los individuos (Evans y Reid, 2016).

Hoy, la autorresponsabilidad social es una cortina de humo para encubrir las fallas sanitarias latentes en las sociedades capitalistas afiliadas al neoliberalismo global y a las políticas de Estados subalternas. Y, por otro lado, esa cortina sirve de telón testimonial de las buenas obras gubernamentales durante la crisis. Las medidas adoptadas para la Nueva Normalidad hacen, en términos etopolíticos según Rose (2001), que el autogobierno [cuidado y responsabilidad propia] de las personas con su salud sea asociado verticalmente con la visión de un buen Estado. Pero cuánto de verdad hay ahí; valdría preguntar si, con esta moral social del auto-cuidado y la responsabilidad, las sociedades logran subvertir la fragilidad que hoy desnuda la crisis epidémica del Covid-19.

\section{LA SUBVERSIÓN Y ANTIFRAGILIDAD NECESARIAS}

Hasta aquí ha sido argumentado cómo la política de Nueva Normalidad es inconsistente con la ontología cambiante de la normalidad, pues ella nos promete un tiempo futuro posterior a la vacunación contra el SARS-CoV2, pero no nos promete un espacio diferente al político y socioeconómico causante de las condiciones bases donde el virus ha hecho estragos. Ella recupera la praxis reformista del Estado sobre la sociedad y la actualiza con el discurso retórico de la autorresponsabilidad y la resiliencia colectiva.

La disyuntiva que brota de este terreno políticamente 'estabilizado' es cuán suficiente serán el auto-cuidado, la autorresponsabilidad y la resiliencia para lograr una mejor vida para todos. Y como problematización de esto, basta decir que se ha inferido que la pandemia Covid-19 es consecuencia secundaria de la depredación ambiental y la globalización ingénitos del modelo de desarrollo económico imperante (Cerrillo. 2020), actualmente mantenido por los Estados.

¿Podemos vislumbrar entonces alguna solución a esta disyuntiva? A opinión personal creo que hay dos funciones, directamente proporcionales, que sirven para pensar las opciones remediadoras: una es la subversión y la otra, la antifragilidad.

Tal parece que, en la normalización de vida social hasta ahora lograda, la palabra subversión ha perdido su presencia y fuerza popular (Piastro, 2019). Quizás por ello, es que, en tiempos de Covid-19, adoptamos otras palabras más tolerantes. Para la connotación espaciotemporal del regreso a la normalidad anterior, preferimos palabras como: reversión, inversión y diversión; y para la connotación socio-moral preferimos: introversión y aversión.

Véase que la normalidad capitalista de libre mercado y consumo se ha caracterizado por la inversión de diversos capitales y bienes, así como por la diversión; el tiempo representa inversión, y el espacio, diversión. Invertimos horas del día y de la vida en el trabajo, las relaciones sociales de conveniencia, y en la especialización pro competitiva; utilizamos los espacios del planeta y los virtuales como divertimento de consumo y 
satisfacción. La población joven de hoy está caracterizada por el tiempo acelerado y aprovechable, y por los espacios de experiencias efímeras y replicables.

Por su parte, la situación epidémica de miedo y aislamiento ha reforzado la individuación de la subjetividad y la aceptación exclusiva de la opinión propia; en otras palabras, la gente se habla a sí misma de los problemas externos y ello lleva a posturas radicales de opinión que repercuten en disensos colectivos y discriminación de otras subjetividades. Crece la aversión por los otros, por los amenazantes enfermos y por aquellos que poseen un criterio diferente sobre las medidas gubernamentales dictadas.

Todas estas palabras parecen más adecuadas para los momentos críticos actuales que la palabra subversión. Y no se me entienda mal, por favor. No aludo a subvertir el orden social fundado en el respeto y la unidad, sino asumir al subvertir como una manera de trastocar la normalidad que causa daño y no es compatible con lo que las personas quieren y necesitan. Por tanto, subvertir no tiene peso práctico si antes no se ha advertido esa incompatibilidad. Mientras el pueblo esté ciego o ajeno, no hay subversión que impulse el cambio beneficioso del movimiento normal del sistema social. Mientras continuemos viviendo desposeídos del subvertir propio de lo humano y de la sociedad, seguiremos anhelando el regreso a esa anterior normalidad que tan incompatible es con la humanidad y la naturaleza.

La subversión es consustancial a la diferencia, el conflicto y la reinvención. Esto funda no solamente los diálogos, discusiones, disputas y consensos, sino también la discontinuidad de condiciones que han sido continuas. Por medio de la subversión las condiciones socioeconómicas que los Estados se empeñan en conservar pueden ser discontinuadas y reinventadas. La fragilidad de la población pobre que hoy es visibilizada con la crisis sanitaria fragilidad provocada por la desigualdad social, la discriminación y la marginación inherente al modelo neoliberal puede ser revertida a positivo.

Las fragilidades de las sociedades contemporáneas en general deben ser revertidas no hacia la fortaleza o robustez, sino hacia la antifragilidad. En este sentido la antifragilidad viene a ser una característica compuesta por el conjunto de cualidades y habilidades de entidades con comportamientos sistémicos que se ajustan, aprenden y adaptan a los imprevisibles cambios internos y externos del medio.

Taleb (2013) propuso este concepto para evitar el uso de otros inacertados conceptos similares. Robustez o resiliencia son los dos términos que desestima el autor a la hora de teorizar sobre los procesos de cambios y persistencias en un mundo aleatorio e incierto. Para este pesador libanés, la antifragilidad supera las limitaciones de grado entre lo débil [frágil] y lo fuerte [robusto], así como la regresión condicional de los comportamientos resilientes que rescatan un estado anterior de estabilidad. Similarmente, la antifragilidad comparte con estas nociones la realidad dinámica, aleatoria y volátil de la vida en el mundo. Sin embargo, lo conveniente de hablar de ella es que desvela lo beneficioso del cambio a través del tiempo que asegura la perdurabilidad y supervivencia del sistema. Ella está en cada persona y sociedad; es característica del sistema económico, político y social. Es un factor imprescindible en la prosperidad y crecimientos de estos a medida que la ocurrencia de crisis le favorece organizativa, estructural y operativamente. 
A pesar de todo, lo benéfico de la antifragilidad tiene una delgada frontera con lo perjudicial. Cabe resaltar que no toda crisis es provechosa para las sociedades, y menos cuando tienen repercusiones negativas elevadas. En este sentido, la antifragilidad está en llevar a un nivel tolerante de fragilidad a las sociedades que enfrentan diversas crisis, de manera tal que puedan afrontarla y superarla benéficamente. Con ello se logra construir progresivamente un comportamiento de reacción que evita el quiebre o ruptura de las sociedades a causa de las crisis; ellas dejan de estar peligrosamente frágiles para estar garantizadamente antifrágiles.

El logro definitivo de la política que asuma a la antifragilidad como directriz de su impacto social es conformar un sistema social que no ceda ante los acontecimientos imprevisibles, perturbaciones o disruptores, y que facilite su acople a la volatilidad y aleatoriedad de los fenómenos del mundo. Para lograrlo hoy es imprescindible que los Estados atiendan a los errores político-económicos que, en el contemporáneo mundo capitalista y globalizado, ha fragilizado a las sociedades. La reparación de estos errores lleva a diseñar mecanismos que propicien la distribución de la riqueza, la educación masiva y la salud pública, entre otros.

Lo inadecuado de la política de Nueva Normalidad que hoy rige las vidas en Latinoamérica y otras latitudes es que, tácitamente, recurre a una anti-fragilidad para connotar renuencia ante la fragilidad. Esto lo hace por medio de denotativos que evidencian la debilidad del sistema, tales como: mantener el equilibrio entre economía y salud (Gobierno de la Ciudad de México, 2020) en una sociedad con una salud económicamente privatizada que, además, no puede apoyar económicamente a las personas enfermas. Esto conduce sociopolíticamente al remarque de las dicotomías sociales entre los fuertes y los débiles, ricos y pobres, privilegiados y marginados. Las sociedades actuales necesitan de la antifragilidad, no de la supresión de las fragilidades que, de una manera u otra, siempre estarán presentes. De haber sido antifrágiles, hoy los pobres no serían más pobres, ni las personas vulnerables en confinamiento estarían camino a la pobreza.

En estos términos, la antifragilidad debe ser admitida como una propiedad de la normalidad capaz de normalizar los cambios agresivos o crisis consideradas desnormalizantes, y que reniegue la conservación de los factores estructurales del sistema que mantienen las fragilidades lesivas. De ahí que la antifragilidad sea axioma de una moral sociopolítica de responsabilidad mutua, o sea, bastión de una ética de corresponsabilidad absoluta para pueblos e instituciones que permita subsanar los errores y evitar futuras fallas.

Pero, para lograr esta moral, es necesario subvertir el axioma ético capitalista donde la anti-fragilidad de unos se da a costa de la fragilidad de otros dentro de un capitalismo axiomatizado en la competencia, la acumulación de capital y el crecimiento desigual (Berardi, 2020). Es imperioso transfigurar este axioma en la siguiente norma política: es un derecho social gozar de antifragilidad en pro de evitar la fragilidad de otros. Y con esto concluyo. 


\section{REFERENCIAS BIBLIOGRÁFICAS}

AFP. (2020, 22 de octubre). El FMI elogia la respuesta de Uruguay a la pandemia: "deja mucho que envidiar". La Nación. https://www.lanacion.com.ar/el-mundo/ coronavirus-uruguay-deja-mucho-envidiar-region-segun-nid2486779

Arteta, I. (2020, 12 de agosto). Hacer obligatorio el cubrebocas genera riesgo de violación de derechos: Gatell. Animal Político. https://www.animalpolitico.com/2020/08/ cubrebocas-obligatorio-violacion-derechos-gatell/

Barría, C. (2020, 21 de junio). Coronavirus en América Latina: los países en que se prevén las mayores caídas económicas este año (y los que serán menos golpeados). BBC News. https://www.bbc.com/mundo/noticias-53438543

Berardi, F. (2020, 17 de marzo). Chronicles of the psycho-deflation. Nero. https://www.neroeditions.com/chronicles-of-the-psycho-deflation/

Cerrillo, A. (2020, 8 de septiembre). La degradación ambiental catapulta las pandemias. La Vanguadia. https://www.lavanguardia.com/natural/20200908/483359329249 /degradacion-ambiental-catapulta-pandemias.html

D’Antonio, W. V. y Pike, F. B. (Eds.) (1964). Religion, Revolution, and Reform. New Forces for Change in Latin America. London: Burns \& Oates Ltd.

De Sousa, B. (2006). Conocer desde el Sur. Para una cultura política emancipatoria. Lima: Fondo Editorial de la Facultad de Ciencias Sociales/Programa de Estudios sobre Democracia y Transformación Global.

Del Castillo, R. (2003). Pragmatismo reformista, pragmatismo radical. Respuesta a "Viejo y nuevo pragmatismo" de Susan Haack. Diánoia, 48 (50): 145-180. https://doi.org/10.22201/iifs.18704913e.2003.50

Durán, C. (2020, 22 de abril). ¿Una nueva normalidad? El Desconcierto. https://www.eldesconcierto.cl/opinion/2020/04/22/una-nueva-normalidad.html

EFE (2020, 12 de octubre). Panamá inicia su "nueva normalidad" con cautela y resiliencia. Agencia EFE. https://www.efe.com/efe/america/economia/panama-inicia-sunueva-normalidad-con-cautela-y-resiliencia/20000011-4365924

Evans, B. y Reid, J. (2016). Una vida en resiliencia. El arte de vivir en peligro (Trad. V. Altamirano). Ciudad de México: Fondo de Cultura Económica.

Figueroa, J. G. (2020). Algunas reflexiones sobre dilemas éticos del cuidado en un entorno de pandemia. Psicologia \& Sociedade, 32: 1-18. http://dx.doi.org/10.1590/18070310/2020v32239528

Fonseca, M. (2020). La “nueva normalidad” post-covid-19: más neoliberalismo, desastre y pobreza. Revista Análisis de la Realidad Nacional, 9 (190): 104-138. http://ipn.usac.edu.gt/wp-content/uploads/2020/08/IPN-RD-190.pdf

Galindo, J. (2020, 13 de septiembre). América Latina explora su nueva normalidad. El País. https://elpais.com/sociedad/2020-09-13/america-latina-explora-su-nuevanormalidad.html 
Garcia, V. (2020, 6 de mayo). Piñera frena el plan de "nueva normalidad" por el avance del virus. La Nación. https://www.lanacion.com.ar/el-mundo/pinera-frena-plannueva-normalidad-avance-del-nid2362346

Gobierno de Jalisco (2020, 1 de julio). Boletín No. 257 Diabetes, hipertensión y obesidad potencializan riesgo de COVID-19. https://ssj.jalisco.gob.mx/prensa/noticia/ 9181

Gobierno de la Ciudad de México (2020). Plan Gradual hacia la Nueva Normalidad en la Ciudad de México. https://covid19.cdmx.gob.mx/nuevanormalidad

González, S. (2018). Reformismo o revolución. Las coordenadas de un nuevo debate. Un debate que se inicia (1994). En M. A. Gandásegui, D. Castillo y A. Carrera (Coords.) Antología del pensamiento crítico panameño contemporáneo (pp.425-437). Buenos Aires: CLACSO. https://www.jstor.org/stable/pdf/j.ctvfjd163.22.pdf

Guimerá, A. (1996). Introducción. En A. Guimerá (Ed.) El reformismo borbónico. Una visión interdisciplinar (pp. 9-33). Madrid: Alianza Editorial.

ONU Noticias (2020, 5 de junio). Coronavirus: la OMS recomienda el uso de mascarillas para toda la población, pero advierte que pueden dar una falsa seguridad. https://news.un.org/es/story/2020/06/1475562

Piastro, J. (2019). Los lenguajes de la identidad. La subversión como creación. Barcelona: Herder.

Redacción de El País (2020, 15 de abril). Coronavirus: ¿qué dijeron los uruguayos sobre su confianza en los informes oficiales y las medidas adoptadas? El País. https://www.elpais.com.uy/informacion/sociedad/coronavirus-dijeron-uruguayo s-confianza-informes-oficiales-medidas-adoptadas.html

Redacción de Montevideo Portal (2020, 3 de junio). Un 65\% de los uruguayos confía en las medidas del gobierno ante el COVID-19, según Cifra. Montevideo Portal. https://www.montevideo.com.uy/Noticias/Un-65-de-los-uruguayos-confia-enlas-medidas-del-gobierno-ante-el-COVID-19-segunCifra-uc754632

Redacción Médica (2020, 13 de octubre). "El coronavirus no es una pandemia. Es una 'sindemia”. Redacción Médica. https://www.redaccionmedica.com/secciones/ sanidad-hoy/sindemia-coronavirus-pandemia-significado--8888

Reuters (2020, 11 de agosto) Crisis del coronavirus desata conflictos sociales en Perú. El Economista. https://www.eleconomista.com.mx/internacionales/Crisis-delcoronavirus-desata-conflictos-sociales-en-Peru-20200811-0029.html

Rose, N. (2001). The politics of life itself. Theory, Culture \& Society, 18 (6): 1-30.

Rose, N. (2012). Política de la vida. Biomedicina, poder y subjetividad en el siglo XXI (Trad. E. Luján). La Plata: UNIPE Editorial Universitaria.

Shepherd, K. (2020, 13 de mayo). Tensions over restrictions spark violence and defiance among protesters as Trump pushes states to reopen. The Washington Post. https://www.washingtonpost.com/nation/2020/05/13/protest-violencecoronavirus/ 
Stewart, E. (220, 7 de agosto). Anti-maskers explain themselves. Vox journal. https://www.vox.com/thegoods/2020/8/7/21357400/anti-mask-protest-ralliesdonald-trump-covid-19

Taleb, N. N. (2013). Antifrágil. Las cosas que se benefician del desorden (Trad. G. Sánchez y A. Santos. Barcelona: Paidós.

Vecinday, L. (2017). La orientación de la política social en el ciclo de recuperación “posneoliberal” en Uruguay (2005-2015). Serviço Social \& Sociedade, 129: 245-264. https://doi.org/10.1590/0101-6628.107.

CITAR COMO:

Montero Rodríguez, J. L. (2021). La política de Nueva Normalidad bajo el lente de la filosofía social. Puriq, 3(1), 55-70. https://doi.org/10.37073/puriq.3.1.141 